\title{
EVALUATION OF THE EFFECTIVENESS OF FREE NICOTINE PATCH THERAPY IN A CHARITY CLINIC FOR SMOKING CESSATION
}

\author{
Salmeen D.Babelghaith ${ }^{1}$, Faisal A. Alqarni ${ }^{1}$, Syed wajid ${ }^{1 *}$, Wael H. Mansy ${ }^{1}$, \\ Sultan Alghadeer ${ }^{1}$ and Mohammed N. Alarifi ${ }^{1}$
}

\author{
1 Department of Clinical \\ Pharmacy, College of \\ Pharmacy, King Saud \\ University \\ P. 0. BOX 2454, 11451, \\ Riyadh, Saudi Arabia
}

Submitted: 01-09-2016 Revised: $15-10-2016$ Accepted: 25-11-2016

*Corresponding author Syed wajid

Email:

wali@ksu.edu.sa

\begin{abstract}
The purpose of this study was to evaluate the efficacy of a free nicotine- patch therapy for smoking cessation in Saudi smokers. A single centered prospective study was carried out in a charity clinic for smoking cessation in Riyadh, Saudi Arabia. A total of 31 subjects who attended the smoking cessation clinic from June 2014 to August 2014 were studied. All participants were male and their mean age was $31.1 \pm 6.4$ years. The duration of history of smoking was $12.9 \pm 6.8$ years. The nicotine- patch therapy outcomes were measured at baseline and at 6 weeks after using nicotine- patch therapy. At base line the number of cigarettes per day was $27 \pm 10$ and carbon monoxide (CO) level was $20.2 \pm 8.3$. The analyzed statistics revealed that there were significant decreased in the number of cigarette per day $(p=0.001)$ and Carbon Monoxide (CO) level $(p=0.001)$ over 6 weeks of nicotine- patch therapy. After 6 weeks of therapy, abstinence rate was $58 \%$ (verified by CO level) and no serious adverse reactions were documented. The most common side effects were nausea, headache and local irritation sings. In addition, our finding revealed that smokers were likely to suffer from withdrawal symptoms following trying to quit. These withdrawal symptoms include sleep disturbance, loss of concentration and weight gain as well as irritability. Results of this study show that free nicotine-patch therapy is an effective measure for smoking cessation in Saudi population.
\end{abstract}

Keywords: nicotine patch therapy, smoking cessation clinic, side effects

\section{INTRODUCTION}

Smoking is major public health problem and a condition that leads to increase morbidity and mortality (Fiore et al., 2008). The World Health Organization (WHO) statistics showed more than 5 million of people killed per year due to tobacco use (WHO, 2014). It has been postulated that the number of tobacco- related deaths worldwide in the year 2020 could increase to 8.4 million (Al-Rifi, 2004). Complications related to smoking are cancer, heart disease, stroke, and chronic obstructive pulmonary disease (Preechawong et al., 2011).

Smoking in Saudi Arabia influenced by cultural and environment; the country has history of smoking more than 50 years (Al-Rifi, 2004). Patterns of smoking in Saudi population include cigarette and other smoking pastemixture such as Jurake and mehassel (Al-Arifi et al., 2006). Consequently, smoking is major public health issue in Saudi Arabia, as it has been estimated that 2.4 -52.4\% of Saudi Arabia are smoker (Bassiony, 2009). Among adolescents, the prevalence of current smoking ranges from 15\%-30\%.(Jarallah et al., 1996; Lam et al., 2005). In addition, smoking is not only dangerous to people but contributing to be social cost. Saudi Arabia spends around $\$ 315$ million for purchasing tobacco every year (Bassiony, 2009).

The most effective intervention of reducing serious complications in smokers is to quit smoking (Lam et al., 2005). Nicotine- patch therapy is an effective pharmacological assist for smokers attempting to quit, and it has been evidenced as first line treatment for smoking cessation (Xiao et al., 2014). However, limited smoking cessation studies established in Asian populations have been established in China, and Taiwan (Lam et al., 2005; Hsueh et al., 2010, 
Xiao et al., 2014). In addition, there is little data from the Middle East namely Kingdom of Saudi Arabia focusing on ethnic differences in tobacco dependence, smoking cessation and behavioral aspects of quitting smoking.

Free nicotine patch program has shown significant impact in helping certain ethnicity to quit smoking achieving an abstinence rate of $26.7 \%$ in 4 months follow-up period among Asian American population in the United States (Shelley et al., 2010). Several charity and free smoking cessation programs and clinics are available in Saudi Arabia; however, to best of our knowledge, no study was conducted to evaluate the efficacy, safety and tolerability of nicotine- patch therapy programs. Therefore, this study was done to investigate the effectiveness of a free nicotine- patch therapy for smoking cessation in Saudi Arabia.

\section{MATERIAL AND METHODS}

The current study was a single centered prospective study to evaluate the efficacy of a free nicotine-patch therapy in Saudi smokers through the period from June 2014 to August 2014. In addition to the efficacy, the safety of nicotine patch was assessed. The subjects were enrolled from a charity clinic for smoking cessation in Riyadh, Saudi Arabia. Any Saudi smoker who ages 18 years or older and smokes at least 10 cigarettes per day was included in the study. Subjects were excluded if subjects: (1) were using tobacco-containing products other than cigarettes;(2) were pregnant women; (3) had cardiovascular diseases; (4) used nicotine NRT within 6 months; (5) had a level of carbon monoxide less than 10 parts per million (ppm); (5) were diagnosed with psychiatric condition. Data collected included: socio-demographic data, physical examination, medical history and vital signs assessed by the clinic physicians, and analysis of an expired carbon monoxide (CO) sample. All these date were taken from patient's profile.

\section{Intervention}

The smoking cessation program was a 6week program of free nicotine-patch therapy. Every subject received $21 \mathrm{mg}$ per day during the first and second week, $14 \mathrm{mg}$ per day during the third and fourth week and $7 \mathrm{mg}$ per day during the fifth and sixth week. Proper application and usage of nicotine patch were delivered to all our study's subjects. The ethical approval was obtained from King Saud University College of Pharmacy. All participants were informed and briefed on the study. Then, they signed a written consent and scheduled for a medical screening examination.

\section{Measures}

Subjects attended the clinic weekly. Evaluations were done at baseline before the intervention of nicotine -patch therapy and at the sixth week visit after completing the treatment regimen. At baseline, data on number of cigarettes per day, CO levels, smoking history and patients' demographic data were obtained. The data collections were repeated after 6 weeks of receiving nicotine- patch therapy. The outcome of the nicotine-patch therapy was measured as changes in the number of cigarettes per day, the CO level, and abstinence rates. In addition, the adverse events were assessed by interviewing the participants.

\section{Safety}

The adverse events were assessed by interviewing the participants during their weekly visits. The researchers also reviewed the patient records to determine any adverse events

\section{Efficacy}

Abstinence rates: Smoking abstinence was determined by self-reported cigarette use and verified with a CO level lower than 10 $\mathrm{ppm}$. The assessment of quit smoking included point-prevalence abstinence. The pointprevalence rate of abstinence measured at the 6th-week right after the treatment. Pointprevalence abstinence refers to the percentage of individuals who were not smoking during the previous 7 days (Chen et al., 2002).

$\mathrm{CO}$ levels: The CO levels were assessed by having subjects take a deep breath and hold it for 15 seconds before exhaling into a $\mathrm{CO}$ monitor (Bedfont Micro Smokerlyzer). Levels lower than $10 \mathrm{ppm}$ was indicator of abstinence.

\section{Statistical analysis}

All the data were transferred to the spreadsheet of SPSS version 21 for analysis. Descriptive data were presented as numbers, frequencies, percentages, means and standard 
Table I. The characteristics of participants $(n=31)$

\begin{tabular}{lcc}
\hline Variables & Mean (SD) & n (\%) \\
\hline Age in years & $31.1(6.4)$ & \\
Gender & & $31(100)$ \\
$\quad$ Male & & \\
Education level & & $14(45.2)$ \\
$\quad$ High school & $17(54.8)$ \\
$\quad$ University & $12.9(6.8)$ & \\
The duration of history of smoking in eyras & $27(10)$ & \\
The number of cigarettes per day & $20.2(8.3)$ & \\
Carbon monoxide (CO) level & \\
\hline
\end{tabular}

deviations. Wilcoxon test was used to analyse the significance of variations before and after intervention.

\section{RESULTS AND DISCUSSION} Baseline characteristics

A total of 31 smokers who fulfilled the inclusion criteria were included in the study. The characteristics of participants are shown in Table I. All participants were male. The mean age of participants was $31.1 \pm 6.4$ years. The duration of history of smoking was $12.9 \pm 6.8$ years. The number of cigarettes per day was $27 \pm 10$. The CO level was $20.2 \pm 8.3$.

\section{The outcomes of nicotine patch The number of cigarettes per day}

Reduction of the amount of cigarette smoking per day over the 6 weeks period summarized (Table II). The mean number of cigarette at baseline was 27 cigarette per day $(\mathrm{SD}=10)$ and at 6 weeks was 12.3(SD=16.3). There was significant reduction in the number of cigarette per day at base line and 6 weeks $(p=0.001)$ from the intervention.

\section{co level}

The CO level is an important measure of the efficacy of nicotine-patch therapy. The mean scores of the CO level pre-intervention and after the intervention was $20.2(\mathrm{SD}=8.3)$, $11.1(\mathrm{SD}=12.6)$ respectively (Table II). There was significant reduction in $\mathrm{CO}$ level after inter-vention of nicotine-patch therapy $(p=0.001)$.

\section{Abstinence rates}

The point-prevalence rates of abstinence from smoking, as verified by CO levels showed that subjects were abstinent at $58 \%$ at 6 weeks (18 of 31 subjects).

\section{Adverse reactions}

The majority of adverse reactions reported during the period of study were headache $(19.3 \%)$, followed by itching (16.1) and redness (12.9). Table 3 shows others adverse reactions were reported. In addition only one participant of non quit smokers had adverse reaction namely headache.

\section{Withdrawal symptoms}

Withdrawal symptoms of smoking were sleep disturbance $(35.4 \%)$, irritability $(35.4 \%)$ and loss of concentration (48.4\%) (Table IV).

The present study evaluated the effectiveness and safety of nicotine-patch therapy in a population of Saudi Arabia. To our knowledge this was first smoking cessation carried out in Saudi Arabia smokers. The finding of this study revealed that nicotinepatch therapy for smoking cessation appeared to be safe and effective. These findings were consistent with a study evaluated the efficacy a free nicotine-patch program among Chinese American smokers living in New York City (Shelley et al., 2010). A total of 375 subjects from two community-based organizations were enrolled to receive free nicotine patch therapy. Baseline and 4-months follow-up survey were used to determine the abstinence rate. The abstinence rate at 4 months was $26.7 \%$. One of the main outcomes of smoking cessation is 
Table II. The outcomes of nicotine patch therapy $(\mathrm{n}=31)$

\begin{tabular}{llccc}
\hline Smoking status & Variables & $\begin{array}{c}\text { Pre intervention } \\
\text { Mean (SD) }\end{array}$ & $\begin{array}{c}\text { Post intervention } \\
\text { Mean (SD) }\end{array}$ & $\begin{array}{c}\text { P* } \\
\text { value }\end{array}$ \\
\hline Quit smoking & CO level & $16.3(3.8)$ & $2.8(2.1)$ & $\mathrm{P}=0.001$ \\
Continue smoking & Number of cigarette & $22(4)$ & 0.0 & $\mathrm{P}=0.001$ \\
& CO level & $25.6(10.1)$ & $22.8(11.9)$ & $\mathrm{P}=0.067$ \\
Total & Number of cigarette & $33(12)$ & $29(13)$ & $\mathrm{P}=0.017$ \\
& CO level & $20.2(8.3)$ & $11.1(12.6)$ & $\mathrm{P}=0.001$ \\
& Number of cigarette & $27(10)$ & $12(16)$ & $\mathrm{P}=0.001$ \\
\hline
\end{tabular}

*Wilcoxon

Table III. Numbers of participants reporting adverse reaction events

\begin{tabular}{cl}
\hline Adverse events & $\mathbf{n ~ ( \% )}$ \\
\hline Redness & $4(12.9)$ \\
Itching & $5(16.1)$ \\
Headache & $6(19.3)$ \\
Nausea & $4(12.9)$ \\
Others & $2(6.4)$ \\
\hline
\end{tabular}

Table IV. Numbers of participants reporting withdrawal symptoms of smoking

\begin{tabular}{ll}
\hline Withdrawal symptoms & $\mathbf{n} \mathbf{0}$ \\
\hline Sleep disturbance & $11(35.4)$ \\
Weight gain & $8(25.8)$ \\
Irritability & $11(35.4)$ \\
Loss of concentration & $15(48.4)$ \\
Others & $2(6.4)$ \\
\hline
\end{tabular}

abstinence rate. The abstinence rate of this study was $58 \%$ at 6 weeks. The abstinence rate had a high effect in smoking cessation through 6 weeks period of nicotine- patch therapy. Our higher abstinence rate was consistent with other studies (Chou et al., 2004; Paoletti et al., 1996), suggesting that the nicotine patch approach promoted smoking cessation in Saudi pupation.

This study found positive reduction in the number of cigarettes over 6 weeks. This demonstrated that nicotine patch therapy significantly reduce the daily cigarettes smoking. In addition, the significant reduction in CO level supported the reduction in daily cigarette smoking. The result supports the outcomes of previous studies that nicotine patch therapy was effective in smoking reduction verified by reduction in $\mathrm{CO}$ level $\mathrm{s}$ and number of cigarette smoking per day
(Joseph et al., 1996; Chou et al., 2004; Batra et al., 2005; Xiao et al., 2014).

This study confirmed the safety of nicotine - patch therapy amongst the Saudi smokers as reflected from the low prevalence of mild symptoms tolerated by Saudi smokers. This study reported $32.2 \%$ of side effect including systemic events (headache, nausea) and dermatitis disorders. However, our finding are much lower than those reported $(50 \%)$ in USA (Transdermal Nicotine Study Group, 1991). Moreover, a similar study was carried out in china aimed to assess safety of nicotine patch in Chinese smokers reported that 26.3 $\%$ of subjects had gastrointestinal side effects (Xiao et al., 2014). This study showed that the most common withdrawal symptoms were sleep disturbance, loss of concentration, weight gain and irritability. All these withdrawal symptoms are consistent with several previous 
studies (Dorothy et al.,1984; Hajek et al.,1989; Zhang et al., 2006; Tomson et al., 2006).

Although the findings of study are promising, the efficacy and safety of nicotine patch therapy in Saudi population, it has some limitations. One of the limitations is the participation was restricted to male smokers and limited by small size who attended the Naqa Charity Clinic. Therefore, the results of this study could only represent the situation in Riyadh city. Another limitation is the shortterm follow-up of the smoking cessation and reducing rates. Thus, an extended time followup may be needed to demonstrate longitudinal benefits from the nicotine-patch therapy.

\section{CONCLUSION}

This study reported initial data on the safety and efficacy of nicotine patch therapy in Saudi population. The main contribution of this study showed that nicotine patch therapy can be an important adjunct to smoking cessation in Saudi smokers. Six -week abstinence rate showed higher effect after the use of nicotinepatch therapy.

\section{REFERENCES}

Al-Doghether MH., 2001. Do we need national guidelines for smoking cessation? Ann Saudi Med. 21: 3-4.

Al-Rifi M N., 2004. Prevalence of smoking and attitude toward smoking cessation among community pharmacists, Saudi Arabia. J Pharm Tecnol. 20:329-333.

Al-Arifi MN., Alkarfy, K. M., Al-Suwayeh, S . A, Aleissa, K. A., Shabana, E. I., Al-Dhuwaili, A . A., Al-Hassan, M . I., 2006. Levels of ${ }^{210} \mathrm{Po}$ in blood, urine and hair of some Saudi smokers. J Radional Nucl Ch 269:115118.

Bassiony M M., 2009 . Smoking in Saudi Arabia. Saudi Med J . 30: 876-887.

Batra A., Klingler K., Landfeldt B., Friederich HM., Westin A., Danielsson T., 2005. Smoking reduction treatment with $4-\mathrm{mg}$ nicotine gum: a double-blind, randomized, placebo-controlled study. Clin Pharmacol Ther 78: 689_ 696.

Chen R., Ku CH., Lu RB., Chou KR., 2002. The impact of smoking cessation programs on smoking-related health belief and rate of quit-smoking among schizophrenic patients. $J$ Med Sci 22: 215-220.

Chou KR., Chen R., Lee JF., Ku CH, Lu R., 2004. The effectiveness of nicotine-patch therapy for smoking cessation in patients with schizophrenia. Int J Nurs Stud 41:321330.

Dorothy K., Hatsukami Dk., Hughes JR., Pickens RW., Svikis D., 1984. Tobacco withdrawal symptoms: An experimental analysis. Psychopharmacology 84:231 - 236.

Fiore MC., Jaén CR., Baker TB., et al., 2008. Guideline Panel. Treating Tobacco Use and Dependence. 2008 Update. Clinical Practice Guideline. Rockville, MD: U.S. Department of Health and Human Services. Public Health Service, 2008.

Hajek P., Jarvis M J., Belcher M. , Sutherland, G. , Feyerabend ,C., 1989. Effect of smoke-free cigarettes on $24 \mathrm{~h}$ cigarette withdrawal: A double-blind placebo-controlled study . Psychopharmacology 97: 99 - 102

Hsueh KC, Chen CY, Yang YH, Huang CL. Smoking cessation program in outpatient clinics of Family Medicine Department in Taiwan: a longitudinal evaluation. Eval Health Prof . 2010; 33(1): 12-25.

Jarallah J., Bamgboye E., Al-Ansary L., Kalantan K., 1996. Predictors of smoking among male junior secondary school students in Riyadh, Saudi Arabia. Tob Control ;5:26-9.

Joseph AM., Norman SM., Ferry LH., Prochazka AV., Westman EC., Steele BG., Sherman SE., Cleveland M., 
Antonnucio DO., Hartman N., McGovern PG., 1996. The safety of transdermal nicotine as an aid to smoking cessation in patients with cardiac disease. $N$ Engl $J$ Med 35:1792-1798.

Lam TH., Abdullah ASM., Chan SS., Hedley AJ .2005. Hong Kong Council on Smoking and Health Smoking Cessation Health Centre (SCHC) Steering Group. Adherence to nicotine replacement therapy versus quitting smoking among Chinese smokers: a preliminary investigation. Psychopharmacology 177: 400-408.

Paoletti P., Fornai E., Maggiorelli F., Puntoni R., Viegi G., Carrozzi L., et al.1996. Importance of baseline cotinine plasma values in smoking cessation results from a double blind study with nicotine patch. Eur Respir 9, 643-651.

Preechawong S., Vathesathogkit K., Suwanratsamee S., 2011, Effects of Tobacco Cessation Counseling Training on Thai Professional Nurses' Self-efficacy and Cessation Counseling Practices. Pacific Rim Int J Nurs Res 15: 3-12.

Shelley D, Nguyen N, Peng C-H, Chin M, Chang M, Fahs M. Increasing access to evidence-based smoking cessation treatment: effectiveness of a free nicotine patch program among Chinese immigrants. J Immigr Minor Health. 2010;12(2):198-205.

Tomson Toftgård M. , Gilljam H1., Helgason R S., 2006. Symptoms in smokers trying to quit. Tob Indu Dis 3:44-51.

Transdermal Nicotine Study Group 1991. Transdermal nicotine for smoking cessation. Six-month results from two multicenter controlled clinical trials. JAMA 266;3133-3138.

World Health Organization 2014. Why tobacco is a public health priority. (Updated 2014; Accessed 2014 November ). Available from URL: http://www.who.int/tobacco/health _priority/en/index.html

Xiao D., Zhong N., Bai C., Xiu Q., Xie C.D., Hu D., Mao Y., PerfekR H., Kruse E., Li Q., Liu JJ., Wang C.,2014. Nicotine gum or patch treatment for smoking cessation and smoking reduction: a multi-centre study in Chinese physicians. Front Med 8:84-90.

Zhang L., Samet J., Caffo B., Punjab NM., 2006. Cigarette Smoking and Nocturnal Sleep. Am J Epidemiol 164: 529-537. 